\title{
Importance of the traffic model in the reliability estimation of highway bridges
}

\author{
Fatima El Hajj Chehade ${ }^{1,2^{*}}$, Rafic Younes ${ }^{3}$, Fadi Hage Chehade ${ }^{2}$, and Hussein Mroueh ${ }^{1}$ \\ ${ }^{1}$ Laboratory of Civil Engineering and geo-Environment (LGCgE), Lille University, France \\ ${ }^{2}$ Modeling Center, Doctoral School of Science and Technology, Lebanon \\ ${ }^{3}$ Faculty of Engineering, Lebanese University, Lebanon
}

\begin{abstract}
Road bridges are exposed to stochastic traffic loadings that are not simply determined. The international codes for the design and assessment of highway bridges provide some standard trucks that can be used in the design process. Knowing that the traffic can vary considerably from one bridge to another, standard trucks may lead to poorly estimate the reliability in the assessment process. So, the sensitivity of the reliability indices to the load models will be discussed, on one hand by considering the standard truck given by the French Fascicule 61 and on the other hand by adopting real vehicle data from existing weigh-in-motion station. A set of reinforced concrete bridges will be used for the application.
\end{abstract}

\section{Introduction}

Due to the high variability of parameters related to civil infrastructures, such as material, geometrical or loading uncertainties, the reliability theory constitutes the best assessment method for this kind of structures. This theory, initially applied in the field of software assessment, is then transmitted to the field of structural engineering[1].

The particularity of the structural composition of highway bridges, as well as the stochastic nature of vehicle loading, have made road bridges the most suitable infrastructures for the application of the reliability approach in the assessment procedure[2]. However the adopted loading models to perform reliability calculations are often oversimplified and generally lead to poorly estimate the reliability indices. For example a standard truck load has been used in several studies with variable positions and combinations in the transverse direction [3],[4], in the longitudinal direction, the influence line analysis has been used to calculate the worst load effect.

In this paper, the importance of choosing the right traffic model will be proved. For this purpose, two load cases will be considered, the first one is based on the standard truck Bc defined by the French Fascicule 61[5] and the second one is based on realistic data for vehicle loads from a weigh-in-motion station located on Switzerland A1 highway[6].

The flexural limit state will be assessed for a set of 21 simply supported reinforced concrete bridges using the first order reliability method FORM. The bridges are two or

\footnotetext{
* Corresponding author: fatima hc1991@hotmail.com
} 
three lanes (width $\mathrm{w}=9.5$ or 12.5 ) with lengths $L$ ranging from 8 to $20 \mathrm{~m}$. The number of the T-shaped main girders $G$ is 4,5 or 6 .

\section{Reliability approach}

Structural reliability is the probability that a structure will not attain a specified limit state (ultimate or serviceability) at a given period of time. Each limit state can be defined by a particular form of a function called the limit state function or failure function. The general form of a limit state function can be divided into a resistance term $\mathrm{R}$ and a load effect term $\mathrm{S}$ as follow [7]:

$$
G=R-S
$$

The limit state function is expressed in terms of the basic variables $X$ which affect the structural performance, so we obtain the following expression of the limit state function:

$$
G\left(X_{i}\right)=R\left(X_{1}, X_{2}, \ldots, X_{n}\right)-S(D D, L L, \ldots)
$$

Where $R$ is the resistance function of system of random variables which influence the limit state, for example for a concrete section these variables are related to material properties and section dimensions, and $S$ is the random function of load effects resulting from dead loads $D D$ and live loads $L L$.

According to this definition, the space is divided in two zones: the reliable zone and the failure zone. The boundary between these two subspaces is a hyper surface of equation $G(X)$ which is called the failure surface (i.e. $R=S$ ). Thus, the probability of failure $p_{f}$ corresponds to the probability that $G(X)<0$. It is calculated by FORM [8] as follow (see Fig. 1):

1. The random variable vector $\{X\}$ is transformed from the physical variable space (Xspace) to standard normal (Z-space): $\mathrm{G}(\{\mathrm{X}\}) \rightarrow \mathrm{G}(\{\mathrm{Z}\})$.

2. In the standardized space, the reliability index corresponds to the minimum distance between the origin of the space and the limit state surface $\left(\beta=\min \left(\sum \mathrm{z}_{\mathrm{i}}^{2}\right)^{1 / 2}\right)$

3. The first-order approximation is then used to deduce the failure probability from the reliability index: $p_{f}=\Phi(-\beta)$, where $\Phi($.) denotes the cumulative distribution function of the standard normal distribution.

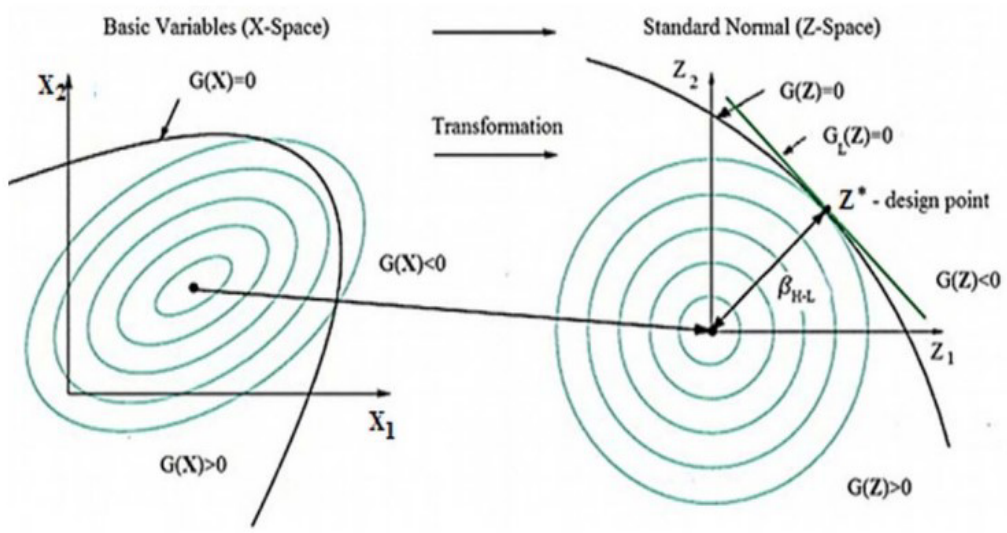

Fig. 1. Illustration of the reliability concept [9] 


\section{Limit state}

The flexural limit state is considered in this study with the following limit state function:

$$
G\left(X_{i}\right)=M_{R}\left(A_{s}, f_{c k}, f_{y k}, d, b_{0}, b_{a}, \ldots\right)-M_{a}\left(M_{s s}, M_{\text {traffic }}, \ldots\right)
$$

where $M_{R}$ is the resistance bending moment and $M_{a}$ is the applied moment resulting from traffic $M_{\text {traffic }}$ and superstructure $M_{s s}$.

\subsection{Resistance moment}

The resistance bending moment in case of T-section is deduced from the rectangular stress distribution given by Eurocode [9]:

$$
\begin{gathered}
M_{R}=A_{s} \times\left(f_{y k} / \gamma_{s}\right) \times(d-s / 2) \\
=A_{s} \times\left(f_{y k} / \gamma_{s}\right) \times\left(d-\left(A_{s} \times\left(f_{y k} / \gamma_{s}\right)\right) / 1.134 f_{c k} b_{0}\right) \text {; neutral axis in the flange } \\
=A_{s} \times\left(f_{y k} / \gamma_{s}\right) \times\left[d-\left(A_{s}\left(f_{y k} / \gamma_{s}\right)-0.567 f_{c k}\left(b_{0}-b_{a}\right) h_{f}\right) / 1.134 f_{c k} b_{0}\right] \text {; neutral axis in the web }
\end{gathered}
$$

where $A_{s}$ is the reinforcement area , $f_{y k}$ is the yield strength of reinforcement, $\gamma_{s}$ is a partial factor for reinforcing steel $=1.15, s$ is the depth of rectangular stress bloc, $f_{c k}$ is the characteristic concrete compressive strength, $d$ is the effective depth of the cross section, $b_{0}$, $b_{a}$ and $h_{f}$ are dimension parameters shown in Fig. 2 .

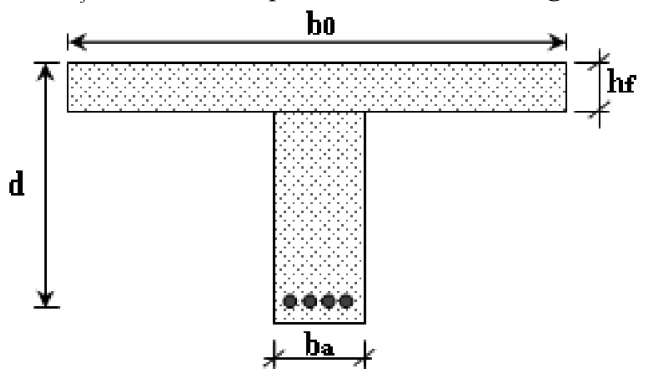

Fig. 2. Cross section of the girder

\subsection{Applied moment}

The applied moment is calculated once by considering trucks from system $\mathrm{B}_{\mathrm{c}}$ described in the Fascicule 61 of the French code and another time by considering realistic traffic from weigh-in-motion WIM data recorded in some European sites.

\subsubsection{System $\mathrm{B}_{\mathrm{c}}$}

The Fascicule 61 presents the calibrated traffic load models used for the design of highway bridges. In this study we will consider the system $\mathrm{Bc}$ for the reliability evaluation. The number of trucks $B_{c}$ in a single queue depends on the bridge length. Trucks are positioned laterally in order to obtain the most critical effect on the studied girder. The system $\mathrm{Bc}$ is presented in Fig. 4. The transverse positions of truck $\mathrm{Bc}$ for a three-lane bridge are illustrated in Fig. 4 with the influence lines of the transverse distribution coefficient for an exterior and an interior girders. 


\subsubsection{Realistic traffic}

The weigh-in-motion WIM data for vehicle simulations are recorded on the Mattstetten motorway in the past 10 years in Switzerland [6]. The recorded parameters of heavy vehicles or trucks (vehicles with weight more than $3.5 \mathrm{t}$ ) can be grouped in twelve classes with number of axles ranging from 0 to 6 . The distribution of gross vehicle weight for each vehicle class is fitted to bimodal beta distribution. An example of the gross vehicle weight generation for the vehicle class $112 \mathrm{r}$ is shown by Fig. 5. Monte Carlo simulation is then used to generate vehicle queues according to the given distribution for each vehicle class.

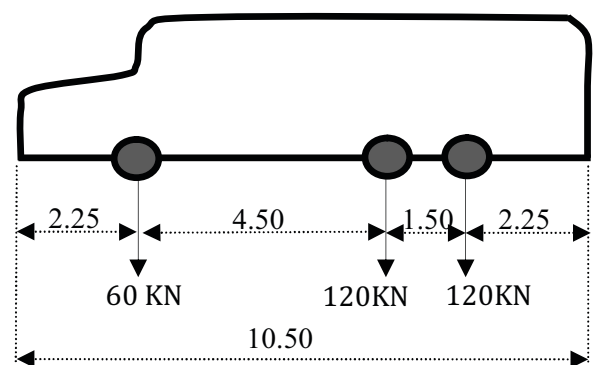

Fig. 3. Longitudinal profile of truck Bc
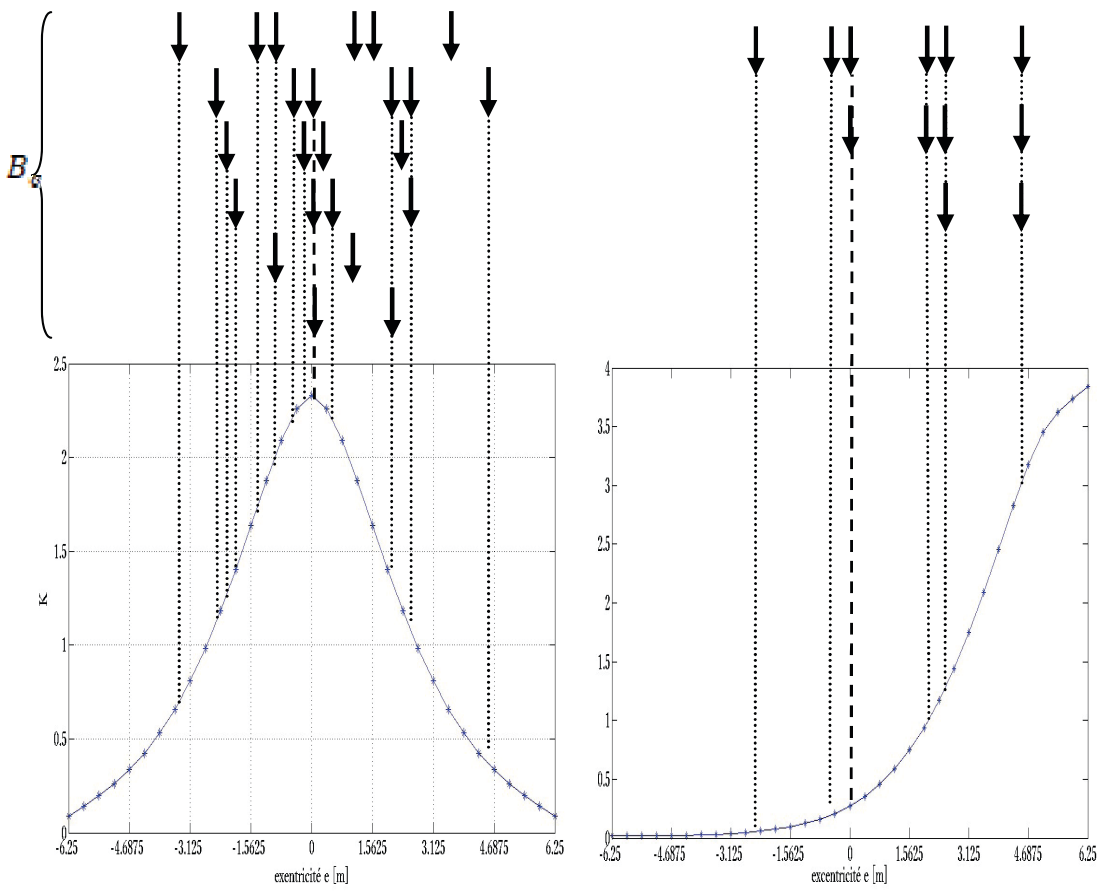

Fig. 4. Transverse positions of system $\mathrm{Bc}$ and influence lines for central and exterior girders 


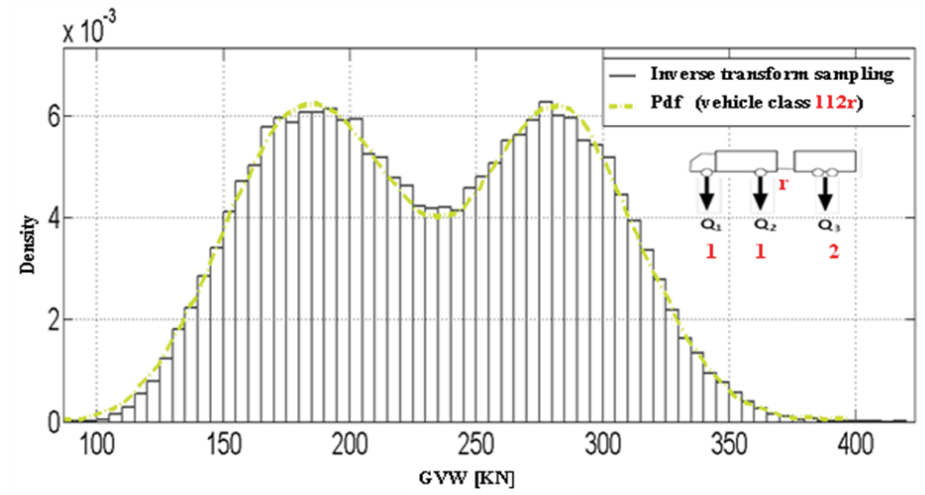

Fig. 5. Gross vehicle weight distribution for the vehicle class $112 \mathrm{r}$

\section{Results and conclusion}

A set of 21 simply supported reinforced concrete bridges with different length L, width w and number of girders $\mathrm{G}$ is used for the calculation of reliability indices. The acronyms of all the bridges, referring to their characteristics, are presented as the labels for the horizontal axis in Fig. 7. The bridges are representative of the existing RC bridges.

A Matlab Toolbox is used to perform reliability calculations using first order reliability method FORM. The performance or limit state function corresponding to the flexural limit state is given by equation (3). This function depends on a set of random variables related to material or geometrical properties and loading conditions.

The distributions of random variables used in the reliability analysis for the entire bridge set are given by Table 1 .

Table 1. Distribution of random variables

\begin{tabular}{|c|c|c|c|c|c|}
\hline Description & Variable & Distribution & Mean & COV & Ref. \\
\hline Area of reinforcement & $A_{s}$ & Normal & Nominal & 0.035 & {$[10]$} \\
\hline Effective height of section & $d$ & Normal & Nominal & 0.0229 & {$[11]$} \\
\hline Yield stress of steel & $f_{v k}$ & Normal & $600(\mathrm{MPa})$ & 0.1 & {$[12]$} \\
\hline Concrete compression strength & $f_{c k}$ & Normal & $40(\mathrm{MPa})$ & 0.15 & {$[12]$} \\
\hline Dead load moment & $M_{D L}$ & Normal & Nominal & 0.07 & {$[11]$} \\
\hline Superstructure moment & $M_{S S}$ & Normal & Nominal & 0.1 & {$[11]$} \\
\hline Live load moment & $M_{L L}$ & Normal & Nominal & - & - \\
\hline
\end{tabular}

Fig.6 presents the reliability indices calculated for the bridge set. A large difference can be noticed between the reliability indices under truck $\mathrm{Bc}$ and those under realistic traffic 
data. When considering realistic traffic data, the increase of the reliability indices is given by Fig. 7 for all the bridges.

The highest increase of the reliability index is about $218 \%$ for the bridge L8w9.5G6 under realistic traffic data as shown by Fig. 7. The average increase for all the bridges is about $140 \%$.

We can deduce that reliability indices are very sensitive to the adopted load case. The standard trucks used for the design of highway bridges don't always represent the real loading conditions and are very general. The use of these standard truck loads for evaluation purpose may lead to underestimate the reliability. So, we should expect early intervention on maintenance for the structural upgrades and strengthening. In other words, this constitutes a waste of money with little efficiency.

The structural evaluation of road bridges, based on traffic loads given by the design standards, is not cost effective. Loading conditions are very special for each bridge. So, traffic monitoring constitutes an important step to get more accurate results about the degree of structural performance. 


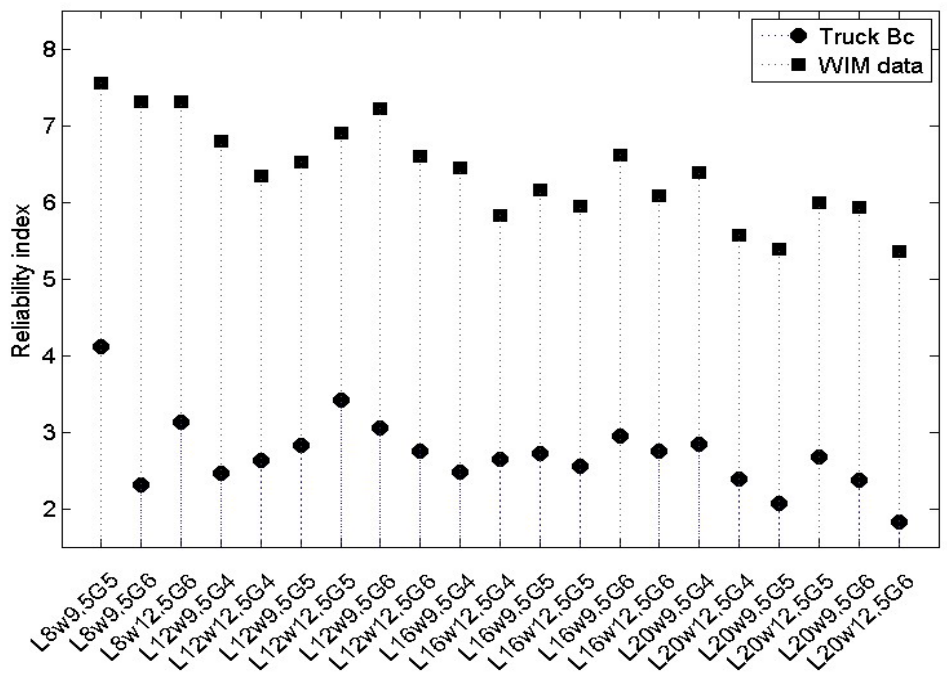

Fig. 6. Reliability indices for the bridge set under truck $\mathrm{Bc}$ and realistic traffic

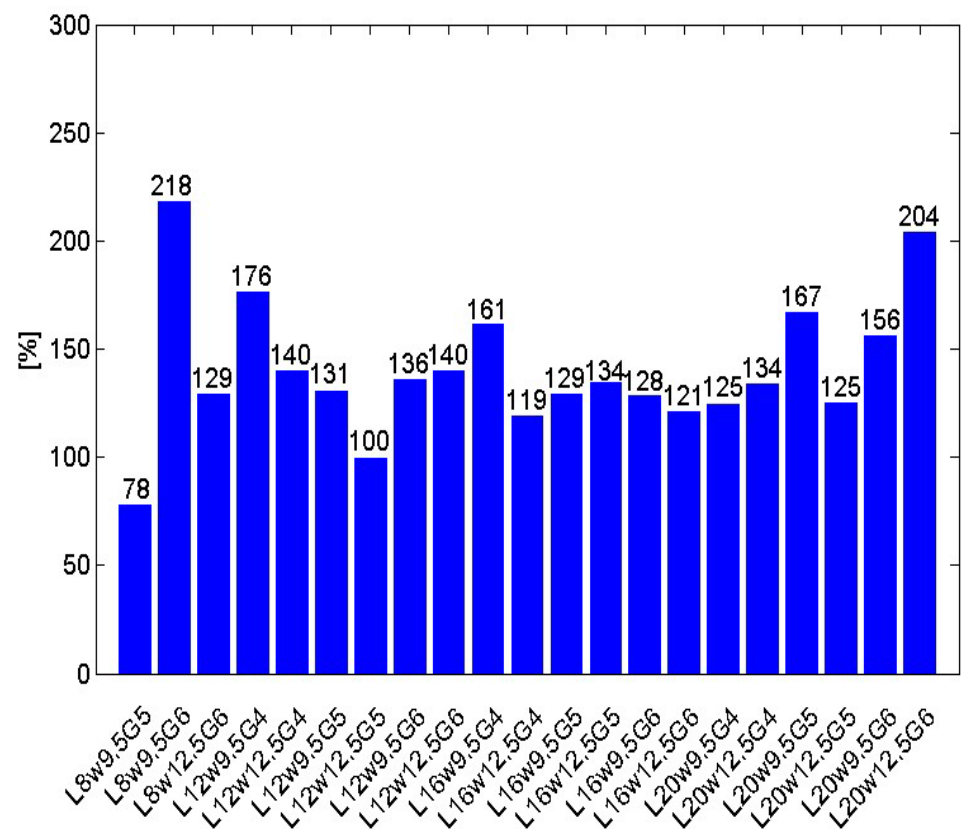

Fig. 7. Percentage increase between reliability indices under realistic traffic and standard truck Bc 


\section{References}

[1] S. S. Bhamare, O. P. Yadav, and A. Rathore, Evolution of reliability engineering discipline over the last six decades: a comprehensive review, Int. J. Reliab. Saf., vol. 1, no. 4, p. 377 (2007).

[2] A. S. Nowak and M. M. Szerszen, Structural reliability as applied to highway bridges, Prog. Struct. Eng. Mater., vol. 2, no. 2, pp. 218-224 (2000).

[3] T. Guo, R. Sause, D. M. Frangopol, and A. Li, Time-dependent reliability of PSC boxgirder bridge considering creep, shrinkage, and corrosion, J. Bridge Eng., vol. 16, no. 1, pp. 29-43 (2010).

[4] B. Tu, Z. Fang, Y. Dong, and D. M. Frangopol, Time-variant reliability analysis of widened deteriorating prestressed concrete bridges considering shrinkage and creep, Eng. Struct., vol. 153, pp. 1-16, Dec. (2017).

[5] Conception, calcul et épreuves des ouvrages d'art titre II. Programmes de charges et épreuves des ponts-routes, FASCICULE 61(1971)

[6] T. Meystre, M. A. Hirt, Office fédéral des routes OFROU, Evaluation de ponts routiers existants avec un modèle de charge de trafic actualisé, Centre de recherche: ICOM EPF-Lausanne, Berne (2006)

[7] Palle Thoft-Christensen and Michael J.Baker, structural reliability theory and its applications. Springer-Verlag Berlin Heidelberg, (1982).

[8] M. Broniatowski and K. G. Hermann, Méthodes Form et Sorm, (2014).

[9] Eurocode 2. Calcul des structures en béton. Partie 1-1: Règles générales et règles pour les bâtiments. AFNOR, (2006)

[10] W. Peng, W. Ye, J. Jia, Z. Lu, and H. Hou, Reliability Assessment of Existing Reinforced Concrete Arch Bridge, Applied Mechanics and Materials, vol. 405-408, Trans Tech Publications, Switzerland, pp. 1687-1690 (2013).

[11] R. de Cassia Silva, Contribution to the probabilistic analysis of reinforced concrete bridge performance, Ecole des Ponts ParisTech, (2004).

[12] E. Bastidas-Arteaga, P. Bressolette, A. Chateauneuf, and M. Sánchez-Silva, Probabilistic lifetime assessment of RC structures under coupled corrosion-fatigue deterioration processes, Struct. Saf., vol. 31, no. 1, pp. 84-96, Jan. (2009). 